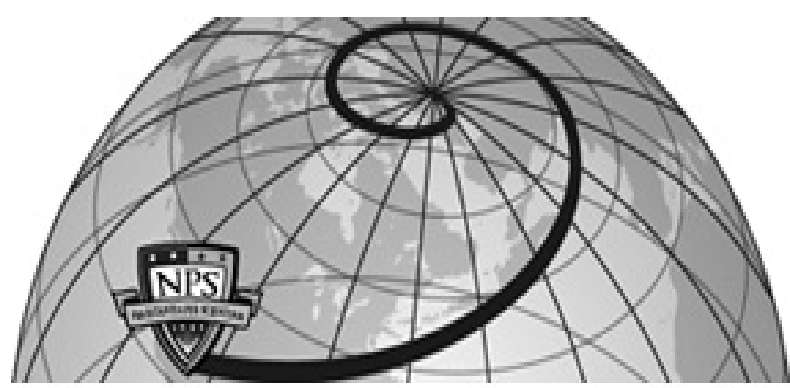

Calhoun: The NPS Institutional Archive DSpace Repository

\title{
Military Cost-Benefit Analysis: Introducing Affordability in Vendor Selection Decisions
}

Melese, Francois; Richter, Anke; Simon, Jay

Monterey, California. Naval Postgraduate School

https://hdl.handle.net/10945/33714

This publication is a work of the U.S. Government as defined in Title 17, United States Code, Section 101. Copyright protection is not available for this work in the United States.

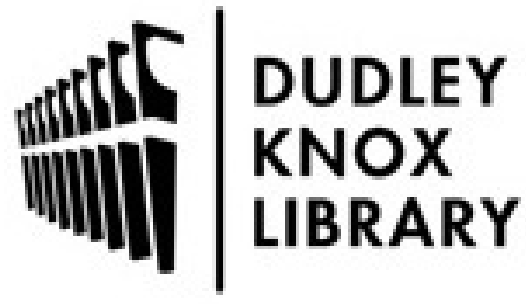

http://www.nps.edu/library
Calhoun is the Naval Postgraduate School's public access digital repository for research materials and institutional publications created by the NPS community. Calhoun is named for Professor of Mathematics Guy K. Calhoun, NPS's first appointed -- and published -- scholarly author.

Dudley Knox Library / Naval Postgraduate School 411 Dyer Road / 1 University Circle Monterey, California USA 93943 
NPS-AM-11-C8P24R02-078

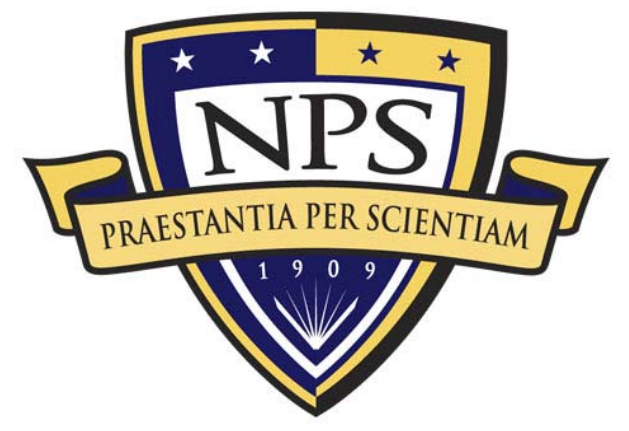

\section{EXCERPT FROM THE \\ PROCEEDINGS}

OF THE

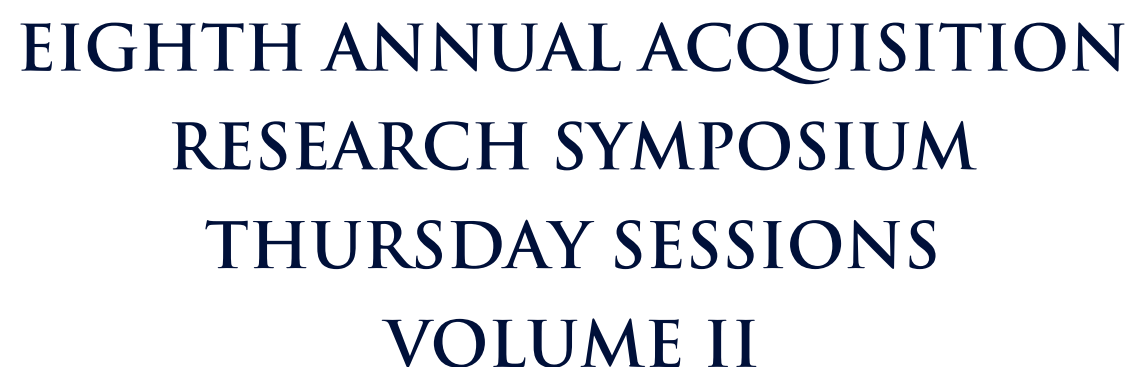

Military Cost-Benefit Analysis: Introducing Affordability in Vendor Selection Decisions

Francois Melese, Anke Richter, and Jay Simon, NPS

Published: 30 April 2011

Approved for public release; distribution unlimited.

Prepared for the Naval Postgraduate School, Monterey, California 93943

Disclaimer: The views represented in this report are those of the authors and do not reflect the official policy position of the Navy, the Department of Defense, or the Federal Government. 
The research presented at the symposium was supported by the Acquisition Chair of the Graduate School of Business \& Public Policy at the Naval Postgraduate School.

To request Defense Acquisition Research or to become a research sponsor, please contact:

NPS Acquisition Research Program

Attn: James B. Greene, RADM, USN, (Ret.)

Acquisition Chair

Graduate School of Business and Public Policy

Naval Postgraduate School

555 Dyer Road, Room 332

Monterey, CA 93943-5103

Tel: (831) 656-2092

Fax: (831) 656-2253

E-mail: jbgreene@nps.edu

Copies of the Acquisition Sponsored Research Reports may be printed from our website www.acquisitionresearch.net 


\section{Preface \& Acknowledgements}

During his internship with the Graduate School of Business \& Public Policy in June 2010, U.S. Air Force Academy Cadet Chase Lane surveyed the activities of the Naval Postgraduate School's Acquisition Research Program in its first seven years. The sheer volume of research products—almost 600 published papers (e.g., technical reports, journal articles, theses) -indicates the extent to which the depth and breadth of acquisition research has increased during these years. Over 300 authors contributed to these works, which means that the pool of those who have had significant intellectual engagement with acquisition issues has increased substantially. The broad range of research topics includes acquisition reform, defense industry, fielding, contracting, interoperability, organizational behavior, risk management, cost estimating, and many others. Approaches range from conceptual and exploratory studies to develop propositions about various aspects of acquisition, to applied and statistical analyses to test specific hypotheses. Methodologies include case studies, modeling, surveys, and experiments. On the whole, such findings make us both grateful for the ARP's progress to date, and hopeful that this progress in research will lead to substantive improvements in the DoD's acquisition outcomes.

As pragmatists, we of course recognize that such change can only occur to the extent that the potential knowledge wrapped up in these products is put to use and tested to determine its value. We take seriously the pernicious effects of the so-called "theorypractice" gap, which would separate the acquisition scholar from the acquisition practitioner, and relegate the scholar's work to mere academic "shelfware." Some design features of our program that we believe help avoid these effects include the following: connecting researchers with practitioners on specific projects; requiring researchers to brief sponsors on project findings as a condition of funding award; "pushing" potentially high-impact research reports (e.g., via overnight shipping) to selected practitioners and policy-makers; and most notably, sponsoring this symposium, which we craft intentionally as an opportunity for fruitful, lasting connections between scholars and practitioners.

A former Defense Acquisition Executive, responding to a comment that academic research was not generally useful in acquisition practice, opined, "That's not their [the academics'] problem-it's ours [the practitioners']. They can only perform research; it's up to us to use it." While we certainly agree with this sentiment, we also recognize that any research, however theoretical, must point to some termination in action; academics have a responsibility to make their work intelligible to practitioners. Thus we continue to seek projects that both comport with solid standards of scholarship, and address relevant acquisition issues. These years of experience have shown us the difficulty in attempting to balance these two objectives, but we are convinced that the attempt is absolutely essential if any real improvement is to be realized.

We gratefully acknowledge the ongoing support and leadership of our sponsors, whose foresight and vision have assured the continuing success of the Acquisition Research Program:

- Office of the Under Secretary of Defense (Acquisition, Technology \& Logistics)

- Program Executive Officer SHIPS

- Commander, Naval Sea Systems Command

- Army Contracting Command, U.S. Army Materiel Command

- Program Manager, Airborne, Maritime and Fixed Station Joint Tactical Radio System 
- Program Executive Officer Integrated Warfare Systems

- Office of the Assistant Secretary of the Air Force (Acquisition)

- Office of the Assistant Secretary of the Army (Acquisition, Logistics, \& Technology)

- Deputy Assistant Secretary of the Navy (Acquisition \& Logistics Management)

- Director, Strategic Systems Programs Office

- Deputy Director, Acquisition Career Management, US Army

- Defense Business Systems Acquisition Executive, Business Transformation Agency

- Office of Procurement and Assistance Management Headquarters, Department of Energy

We also thank the Naval Postgraduate School Foundation and acknowledge its generous contributions in support of this Symposium.

James B. Greene, Jr.

Rear Admiral, U.S. Navy (Ret.)
Keith F. Snider, PhD

Associate Professor 


\title{
Panel 24 - The Other "Big A": Coming to Grips with Affordability
}

\author{
Thursday, May 12, 2011
}

3:30 p.m. - Chair: Reuben Pitts III, President, Lyceum Consulting, LLC

5:00 p.m.

Discussant: Brigadier General Michael E. Williamson, US Army, Joint

Program Executive Officer for the Joint Tactical Radio System

Military Cost-Benefit Analysis: Introducing Affordability in Vendor Selection Decisions

Francois Melese, Anke Richter, and Jay Simon, NPS

On a Quantitative Definition of Affordability

Charles LaCivita and Kent Wall, NPS

Reuben S. Pitts III-President, Lyceum Consulting. Mr. Pitts joined the Naval Weapons Lab in Dahlgren, VA, in June 1968 after graduating from Mississippi State University with a BSME. His early career was spent in ordnance design and weapons systems. He subsequently served on the planning team to reintroduce the Navy to Wallops Island, VA, currently a multiple ship combat, over-the-water weapons testing lab for Surface Ship Combat Systems, Fighter Aircraft, and live missile firings. His outstanding service as the deployed Science Advisor to Commander, U.S. Sixth Fleet was recognized with the Navy's Superior Civilian Service (NSCS) Award and the Navy Science Assistance Program Science Advisor of the Year Award.

Mr. Pitts was selected to lead the technical analysis team in support of the formal JAG investigation of the downing of Iran Air Flight 655 by USS Vincennes, and participated in subsequent briefings to CENTCOM, the Chairman of the Joint Chiefs, and the Secretary of Defense. As Head, Surface Ship Program Office and Aegis Program Manager, Mr. Pitts was awarded a second NSCS, the James Colvard Award, and the John Adolphus Dahlgren Award (Dahlgren's highest honor) for his achievements in the fields of science, engineering, and management. Anticipating the future course of combatant surface ships, Mr. Pitts co-founded the NSWCDD Advanced Computing Technology effort, which eventually became the Aegis/DARPA-sponsored High Performance Distributed Computing Program; the world's most advanced distributed real-time computing technology effort. That effort was the foundation for the Navy's current Open Architecture Initiative.

In 2003 Mr. Pitts accepted responsibility as Technical Director for PEO Integrated Warfare Systems (IWS), the overall technical authority for the PEO. In September of that year, he was reassigned as the Major Program Manager for Integrated Combat Systems in the PEO. In this position, he was the Program Manager for the Combat Systems and Training Systems for all U.S. Navy Surface Combatants, including Aircraft Carriers, Cruisers, Destroyers, Frigates, Amphibious Ships, and auxiliaries. In July, 2006, Mr. Pitts returned to NSWCDD to form and head the Warfare Systems Department. While in this position, he maintained his personal technical involvement as the certification official for Surface Navy Combat Systems. He also served as Chair of the Combat System Configuration Control Board and Chair of the Mission Readiness Review for Operation Burnt Frost, the killing of inoperative satellite USA 193.

Mr. Pitts has been a guest speaker/lecturer/symposium panelist at many NAVSEA-level and DoD symposiums, conferences and at the Naval Postgraduate School, the Defense Systems Management College, and the National Defense University. For 19 years Mr. Pitts was the sole certification authority of all Aegis Combat System computer programs for fleet use. He retired from the U.S. Civil Service in September 2008, with over 40 years of service to the Navy. 
Brigadier General Michael E. Williamson, US Army_Joint Program Executive Officer for the Joint Tactical Radio System.

General Williamson was born in Tucson, Arizona. He was commissioned at the University of Maine as a Second Lieutenant in the Air Defense Artillery in 1983. His assignments include service as the Automation Officer for the 32nd AADCOM in Darmstadt Germany. He then served as a Chaparral Platoon Leader, Vulcan Platoon Leader, Maintenance Officer and Executive Officer in C Battery, 108th Brigade, Hahn Air Force Base, Germany. After attending the Air Defense Artillery Advance Course, he served as the Chief, Forward Area Air Defense Weapons, Development Branch at Fort Bliss, Texas. He then commanded B Battery, 3/1 ADA (Hawk) in the 11th Brigade at Fort Bliss and also in the 31st ADA Brigade at Fort Hood, Texas. After completing command, he served as the Assistant S-3 in the 31st ADA Brigade.

His acquisition experience began as Sr. Military Software Analyst at NATO's military headquarters in Mons, Belgium. He then served as the Associate Director, Battle Command Battle Lab at Fort Leavenworth, Kansas. After attending Command and General Staff College, he served as the Chief of Information Technology, Acquisition Career Management, within the Office of the Assistant Secretary of the Army for Acquisition Logistics and Technology. He was then selected as a Congressional Fellow and served as a legislative assistant to a Member of Congress. After completing the fellowship, General Williamson served as the Product Manager for the Global Command and Control System-Army, and then as the Acquisition Military Assistant to the Secretary of the Army. He served as Commander of Software Engineering Center-Belvoir (SEC-B), He was then assigned as the Project Manager, Future Combat System (Brigade Combat Team) Network Systems' Integration within Program Manager, Future Combat System (Brigade Combat Team). He then served as the Director of Systems Integration, within the Office of the Assistant Secretary of the Army for Acquisition Logistics and Technology. Prior to his current assignment, General Williamson served as the Deputy Program Manager, Program Executive Office, Integration.

General Williamson's awards and decorations include the Legion of Merit with two Oak Leaf Clusters; the Meritorious Service Medal with 2 Oak Leaf Clusters; the Joint Service Commendation medal, the Army Commendation Medal with two Oak Leaf Clusters, the Joint Service Achievement Medal, the Army Achievement Medal with two Oak Leaf Clusters, the Army Superior Unit Award, the National Defense Service Medal with Bronze Star, the Global War on Terrorism Service Ribbon, the Army Service Ribbon, the Overseas Ribbon and the Army Staff Identification Badge.

General Williamson's education includes a Bachelor of Science from Husson College in Business Administration, a Masters of Science in Systems Management from the Naval Postgraduate School and a PhD in Business Administration from Madison University. He also has graduate certificates in Public Policy from the JFK School of Government, Harvard University and the Government Affairs Institute at Georgetown University. He is a graduate of the Army Command and General Staff College, a graduate of the Advanced Management Program at the Harvard Business School and was a Senior Service College Fellow at the University of Texas at Austin. He is Level III certified in Program Management and Communications and Computers. 


\section{Military Cost-Benefit Analysis: Introducing Affordability in Vendor Selection Decisions}

Francois Melese-Professor, Economics, and Deputy Executive Director of the Defense Resources Management Institute (DRMI), NPS. Professor Melese has published over 50 articles and book chapters on a variety of topics and, together with NPS colleagues, was among the first to apply transaction cost economics to generate new insights into military cost estimating. He is a member of Sigma Xi, the Western Economic Association, and the American Economic Association. Dr. Melese joined the DRMI faculty in 1987. [fmelese@nps.edu]

Anke Richter-Associate Professor, NPS. Dr. Richter received a BA in Mathematics and French from Dartmouth College (1991) and a PhD in Operations Research from Stanford University (1996). Her graduate work was supported by a grant from the Office of Naval Research. Dr. Richter was previously a Director of Health Outcomes at RTI-Health Solutions, RTI International. Her research interests include resource allocation for epidemic control, disease modeling and economic impact assessment, and bio terrorism. She has published in numerous journals. Dr. Richter is a member of the Institute for Operations Research and the Management Sciences (INFORMS) and the International Society for Pharmacoeconomics and Outcomes Research (ISPOR). She has published in several peer-reviewed journals, including the Journal of the American Medical Association, Journal of Clinical Epidemiology, PharmacoEconomics, Medical Decision Making, Clinical Therapeutics, and Managed Care Interfaces. Although English is Dr. Richter's first language, she is also fluent in German and French. She joined the NPS faculty in August 2003. [arichter@nps.edu]

Jay Simon-Assistant Professor, Decision Science at the Defense Resources Management Institute (DRMI), NPS. Dr. Simon's main research focus is multiattribute preference modeling. His current and recent work includes a prostate cancer decision model, preference models for health decisions, preferences over geographic outcomes, altruistic utility modeling, and time discounting anomalies. $\mathrm{He}$ is a member of the Institute for Operations Research and the Management Sciences (INFORMS) and the Decision Analysis Society of INFORMS. Dr. Simon joined the DRMI faculty in August 2009. [jrsimon@nps.edu]

\section{Abstract}

This study extends previous research by the authors that focuses on the growing global challenge of affordability. Ballooning public debt burdens are forcing countries around the world to rethink their approaches to procurement decisions. This paper offers a new approach to government vendor selection decisions in major public procurements. A key challenge is for government purchasing agents to select vendors that deliver the best combination of desired non-price attributes at realistic funding levels. The mechanism proposed in this paper is a three-stage, multiattribute, sealed-bid procurement auction. It extends traditional price-only auctions to one in which competition takes place exclusively over attribute bundles. The model reveals benefits in public procurements by defining an alternative in terms of its value to the buyer over a range of possible expenditures, rather than as a single point in budget-value space. This approach leads to some interesting results. In particular, it suggests that in a fiscally constrained environment, the traditional approach of eliminating dominated alternatives could lead to sub-optimal decisions. The final extension of the model explicitly examines the buyer's decision problem under budget uncertainty. The result is in a new metric proposed to evaluate vendors: an expected utility measure of performance. 


\section{Introduction}

This study focuses on the growing global challenge of affordability. Ballooning public debt is forcing countries around the world to rethink their procurement strategies. Recent congressional testimony urges the DoD to "achieve a balanced mix of weapon systems that are affordable" (Written testimony of M. Sullivan , 2009). In the absence of profits to guide public procurement decisions, the challenge is to select vendors that deliver the best possible combination of desired non-price attributes at realistic funding levels. The public procurement mechanism proposed in this paper is a multiattribute sealed-bid procurement auction with multiple budgets.

The U.S. Federal Acquisition Regulation (2005) provided guidance in Subpart 14.5 on a two-step procurement process for government agencies:

Step one consists of the request for, submission, evaluation, and (if necessary) discussion of a technical proposal. No pricing is involved. Step two involves the submission of sealed price bids by those who submitted acceptable technical proposals in step one. Invitations for bids shall be issued only to those offerors submitting acceptable technical proposals in step one. An objective is to permit the development of a sufficiently descriptive and not unduly restrictive statement of the Government's requirements especially useful for complex items.

Blondal (2006) discusses a similar two-stage ${ }^{1}$ bidding process, in which the procuring agency issues a general request and then later issues a detailed request based on the responses.

Much of the multiattribute auction literature, including Che (1993), Beil and Wein (2003), and Parkes and Kalagnanam (2005), either implicitly or explicitly includes price alongside non-price attributes in the buyer's value/utility function. ${ }^{2}$ While this standard approach is appropriate in many private-sector contexts, it generates complications in public procurements such as major defense acquisitions. Unlike the private sector, where the incentive to maximize profits provides a clear objective, the best government decisionmakers can do is to maximize value to the public subject to funding (budget) constraints.

In an application that maximizes value subject to a budget constraint, Michael and Becker (1973) make the case that costs be excluded from measures of value. The authors' focus is on performance and affordability. Vendors compete for a government contract based on their relative costs of producing different components of quality and their unique (sunk) technology investments that define their ability to offer different tradeoffs among these components. A similar approach is known as "cost as an independent variable" (CAIV). Larsen (2007) offers the following explanation of CAIV:

\footnotetext{
${ }^{1}$ Blondal defined stage differently than we do in this paper. We use the term to refer to a decision or set of decisions that depends only on exogenously given parameters and previous decisions. For example, Blondal considers a government agency's offer and the vendor responses to be a single stage, whereas we treat these as two distinct stages. Using our interpretation, Blondal's model is, in fact, a five-stage process.

${ }^{2}$ Value functions are often referred to in defense procurement as measures of effectiveness (MOEs). The term MOE is used in a few different ways. It may describe an attribute itself, a single-attribute value function, or a multiattribute value function, which might incorporate the whole objective's hierarchy, or only a portion of it. For a detailed discussion of MOEs, see Sproles (2000). Regardless, this paper emphasizes using an MOE that includes exclusively non-price attributes.
} 
All acquisition programs/issues consist of three fundamental elements: cost, performance and schedule. Under CAIV, performance and schedule are considered a function of cost. Cost and affordability should be a driving force, not an output after potential solutions are established. (p. 15)

Loerch, Koury, and Maxwell (1999) discuss a Value Added Analysis approach for applying multiattribute preferences to optimize the United States Army's force structure under a budget constraint, in accordance with the CAIV concept. The scope of our model differs from theirs, in that we focus on a single acquisition program. This allows us to incorporate vendors' decision-making into the model, along with issues of asymmetric information. In our model, as in theirs, prices and costs do not appear in the buyer's value function. Instead, the buyer provides information about possible budget levels, allowing prices to appear in affordability constraints in the spirit of CAIV.

Budget constraints may not be known when the vendor selection decision is made. Buede and Bresnick (1999) describe the acquisition process as having four major phases and point out that vendor selection occurs in the first phase, while the budget may change throughout the entire process. Two pioneers in defense economics, Hitch and McKean (1967), advocate determining the maximum effectiveness for a given budget and then examining how each alternative fares under several different budget scenarios. Quade (1989) also advocates evaluating vendor proposals based on a range of possible budgets. This leads to the generation of what we call an "expansion path" for each vendor, which shows how the vendor's proposals change as the budget increases or decreases and thus provides a more complete view of the vendor's ability to provide performance. Our model allows the buyer to offer a set of possible budget levels and solicit vendor proposals for each one, leading to the generation of expansion paths.

Expansion paths reveal valuable information to government procurement agents. Suffering from asymmetric information, buyers have very limited knowledge of the vendors' costs of producing a particular attribute, as well as the technologies (production functions) that combine those attributes into products under consideration. Parkes and Kalagnanam (2005) describe the vendors' private information: "Seller costs can be expected to depend on [the] local manufacturing base and sellers can be expected to be well informed about the cost of (upstream) raw materials" (p. 437). The general motivation for constructing the expansion paths is expressed succinctly by Keeney (2004): "If you do not have the right problem, objectives, alternatives, list of uncertainties, and measures to indicate the degree to which the objectives are achieved, almost any analysis will be worthless" (p. 200). It is imperative in public procurement for alternatives to be adequately described and for any budget uncertainty to be explicitly acknowledged. We emphasize that this can be carried out using a value-focused thinking approach, as discussed by Keeney (1992) and by Parnell (2007) in the context of national defense. That is, it is important for the buyer's evaluation process to be carried out independent of the particular alternatives offered.

In the Model section, we introduce our proposal for a three-stage procurement model. This multiattribute sealed-bid procurement auction emphasizes the use of a value function with exclusively non-price attributes and the specification of a set of possible budget levels. We formulate the decision problems faced by the buyer and the vendors, and discuss various insights derived from the model. We also provide two historical examples of government procurement decisions that likely could have benefited from a more complete formulation of alternatives and specification of uncertainties. 
After vendor bids have been solicited for a spectrum of possible budget levels, the Budget Uncertainty section expands the formulation of the buyer's problem to explicitly include the buyer's beliefs of the probability associated with various budget levels. We follow a decision under uncertainty approach as introduced by Pratt, Raiffa, and Schlaifer (1964). In addition to expressing their beliefs about various budget levels as probabilities, the government buyer specifies a utility function over the value of attribute bundles that incorporates his or her risk attitude, as discussed by Dyer and Sarin (1982) and Matheson and Abbas (2005). The result is a new metric proposed to evaluate vendors: an expected utility measure of performance.

\section{Model}

The procurement agency (the buyer) begins by specifying a multiattribute value function over a set of desired attributes $A=\left\{a_{1}, \ldots, a_{n}\right\}$, as well as a set of (increasing) possible budget levels $B=\left\{b_{1}, \ldots, b_{k}\right\}$. There are $m$ vendors, each of whom will respond in the second stage with a bid. A bid consists of a set of attribute levels that can be produced by a vendor for each of the $k$ possible budget levels. Vendor $j$ 's bid can be expressed as $k$ vectors of the form $A_{j}=\left(a_{1 j}, \ldots, a_{n j}\right)$ for $j=1, \ldots, m$, where $a_{i j}$ is the level of attribute $i$ offered by vendor $j$. Note that unlike bids in most multiattribute auctions, $A_{j}$ does not include any information about price. Instead, the price is captured in the multiple possible budget constraints. The buyer's ultimate decision (the third stage) is to select a vendor $j \in\{1, \ldots, m\}$. The buyer's preferences over the attributes are represented by a value function $V\left(A_{j}\right)$. The same value function is used for all possible realized budget levels.

For ease of exposition, we assume $V\left(A_{j}\right)$ is an additive multiattribute value function similar to that discussed by Keeney and Raiffa (1976) and Kirkwood (1997), although it is later demonstrated the conclusions of the paper do not require $V\left(A_{j}\right)$ to be additive. The use of additive multiattribute value functions requires the assumption of mutual preferential independence (Dyer \& Sarin, 1979; Kirkwood \& Sarin, 1980). This implies that alternatives can be compared exclusively on the set of attributes over which they differ, ignoring levels of other attributes.

For any given budget level, the buyer's objective is as follows:

$$
\max _{j} V\left(A_{j}\right)=\sum_{i=1}^{n} w_{i} v_{i}\left(a_{i j}\right)
$$

where $w_{i}$ is the weight the buyer places on attribute $i: 0 \leq w_{i} \leq 1$, and $\sum w_{i}=1$, and $v_{i}\left(a_{i j}\right)$ is the buyer's single-attribute value function for attribute $i$. We assume that $v_{i}\left(a_{i j}\right)$ is scaled such that the minimum achievable value is zero and the maximum achievable value is one. Note that since $V\left(A_{j}\right)$ is a weighted average of terms between zero and one, it also ranges from zero to one. We assume the buyer has an understanding of the range of attribute levels in determining the weights and that the buyer explicitly shares the weights and the single-attribute value functions. It is necessary for the government buyer to completely specify its preferences to the vendors by providing $w_{i}$ and $v_{i}\left(a_{i j}\right)$ for $i=1, \ldots, n$. The final 
stage of the model involves applying Equation 1 to the set of vendor bids and the buyer selecting the vendor that yields the highest value.

Given the buyer-determined set of desired attributes $A$, along with the weights and single-attribute value functions, and the set of possible budget levels $B$, each vendor produces an attribute bundle to submit to the buyer for each of the $k$ possible budget constraints. Since vendors have private information about their own production capabilities, costs, and profit requirements, each vendor forms his or her own private beliefs about the likelihood of a bid being accepted. ${ }^{3}$ We assume that all vendors believe the probability of a bid being accepted is increasing in $V\left(A_{j}\right)$ for all possible budget levels.

The problem faced by a representative vendor $j$ for an arbitrary budget level $b$ can be expressed as follows:

$$
\begin{gathered}
\max _{a_{i j}} V\left(A_{j}\right)=\sum_{i=1}^{n} w_{i j} v_{i}\left(a_{i j}\right), i=1, \ldots, n \\
\text { subject to } C_{j}\left(v_{i}\left(a_{1 j}\right), \ldots, v_{n}\left(a_{n j}\right)\right) \leq b,
\end{gathered}
$$

where $C_{j}$ is the total cost paid by firm $j$ (with the desired profit margin included) to produce a set of single-attribute values. The cost incurred to generate the corresponding attribute bundle cannot exceed $b$. We assume that $C_{j}$ is increasing in $v_{i}$ for all $i$ and that $C_{j}$ is strictly convex. This condition is not overly restrictive, since it simply implies decreasing returns from vendor investments to improve any individual attribute value. Because the objective function in Equation 2 is linear, given the assumed properties of a representative vendor's cost function, a unique solution (vendor proposal) will exist.

For purposes of illustration, and ease of exposition, the remainder of this study focuses on two vendors and two (non-price) attributes. The two vendors can have different technologies with which to combine the two attributes and may face different costs to improve individual attributes. The Lagrangian function to solve the vendor's problem is given by the following:

$$
L_{j}=w_{1} v_{1}\left(a_{1 j}\right)+w_{2} v_{2}\left(a_{2 j}\right)-\lambda_{j}\left(b-C_{j}\left(v_{1}\left(a_{1 j}\right), v_{2}\left(a_{2 j}\right)\right)\right) \text { for } j=1,2 .
$$

Since an improvement in either attribute increases the value of a particular attribute bundle to the buyer, or $\partial V / \partial v_{i}>0$, each vendor will use the total available budget $b$ to produce its attribute bundle proposal. In this case, first order necessary conditions for an optimum are given by the following:

\footnotetext{
${ }^{3}$ For simplicity, we assume that each vendor determines its required profit margin for each possible budget level proposed by the buyer and that these fixed profit margins are incorporated into the attribute bundles offered. We focus on the vendor's decision of how to allocate fixed amounts of funding across the set of attributes to maximize the value provided to the buyer. Although our results do not require any more details of vendor behavior, we believe this would be an interesting avenue for future research. This exploration could be based on a vendor's search for an optimum bidding strategy in a Dutch auction (see McAfee \& McMillan, 1987, or Milgrom, 1989), which requires a complete formulation of the bidder's beliefs, values, and risk attitude.
} 


$$
\begin{aligned}
& \frac{\partial L_{j}}{\partial v_{1}}=w_{1}+\lambda_{j} \frac{d C_{j}}{d v_{1}}=0 \\
& \frac{\partial L_{j}}{\partial v_{2}}=w_{2}+\lambda_{j} \frac{d C_{j}}{d v_{2}}=0 \\
& \frac{\partial L_{j}}{\partial \lambda_{j}}=b-C_{j}\left(v_{1}\left(a_{1 j}\right), v_{2}\left(a_{2 j}\right)\right)=0,
\end{aligned}
$$

where Equation4c simply asserts that the total budget is being used. Solving Equations $4 a$ and $4 \mathrm{~b}$ yields

$$
\frac{w_{1}}{d C_{j} / d v_{1}}=\frac{w_{2}}{d C_{j} / d v_{2}} .
$$

This implies that the optimum strategy for each vendor is to choose a bid that uses the entire budget and for which the two attributes have equal ratios between the weight placed on the attribute by the buyer and the vendor's marginal cost of increasing the value provided by that attribute. ${ }^{4}$ With two competing vendors, there will be two bids that can be represented by attribute bundles: $\left(a_{11}, a_{21}\right)$ and $\left(a_{12}, a_{22}\right)$.

Of course, cost functions are likely to vary across vendors, meaning that the marginal costs in Equation 5 are likely to vary across vendors as well, resulting in a potentially diverse set of bids. Multiattribute auctions allow vendors to differentiate themselves in the auction process and to bid on their competitive advantages (Wise and Morrison, 2000).

With the buyer's preferences and the vendor's bidding strategy in place, we now demonstrate how a buyer can explore important differences between vendors. Each vendor goes through the process described above for the $k$ different budget estimates, each time producing a bid that satisfies Equation 5 for each of the $k$ possible budgets. This set of bids from a vendor constitutes an expansion path. It tells the buyer precisely how a vendor's bid will change as the budget constraint is relaxed (or tightened). For purposes of illustration, throughout the remainder of the paper, we use a set of six possible budget levels to simulate alternative possible funding constraints: $(\$ 5 \mathrm{M}, \$ 10 \mathrm{M}, \$ 15 \mathrm{M}, \$ 20 \mathrm{M}, \$ 25 \mathrm{M}, \$ 30 \mathrm{M})$ or simply $(5,10,15,20,25,30)$.

Consider the following functional form for the cost functions:

$$
C_{j}\left(v_{1}\left(a_{1 j}\right), v_{2}\left(a_{2 j}\right)\right)=\alpha_{1 j} e^{\beta_{1 j} v_{1}\left(a_{1 j}\right)}+\alpha_{2 j} e^{\beta_{2 j} v_{2}\left(a_{2 j}\right)}, \alpha_{1 j}, \alpha_{2 j}, \beta_{1 j}, \beta_{2 j}>0 \text { for } j=1,2 \text {. }
$$

This particular functional form is separable, in that it consists of the sum of cost functions on the individual attributes. Each individual attribute cost function is increasing and convex, where the exponent $\beta_{i j}$ in Equation 6 determines the convexity of each

\footnotetext{
${ }^{4}$ Note that Equation 5 has a unique solution for each vendor when the entire budget is being used. Because the cost function is strictly convex, as we move along the budget constraint curve, the marginal cost of improving one attribute's value is increasing, and the marginal cost of improving the other attribute's value is decreasing.
} 
function. Although the results of the study do not depend on this particular functional form, this offers a relatively simple way to illustrate our expansion path approach to government vendor selection decisions.

Figure 1 offers an example of an expansion path. The buyer in this example places a weight of 0.7 on Attribute 1 and 0.3 on Attribute 2. The vendor represented in Figure 1, whom we will refer to as Vendor 1, faces lower marginal costs to improve Attribute 1 than to improve Attribute 2 at low levels. Specifically,

$$
\alpha_{11}=2.2, \alpha_{21}=2.7, \beta_{11}=2.0, \beta_{21}=1.7 \text {. }
$$

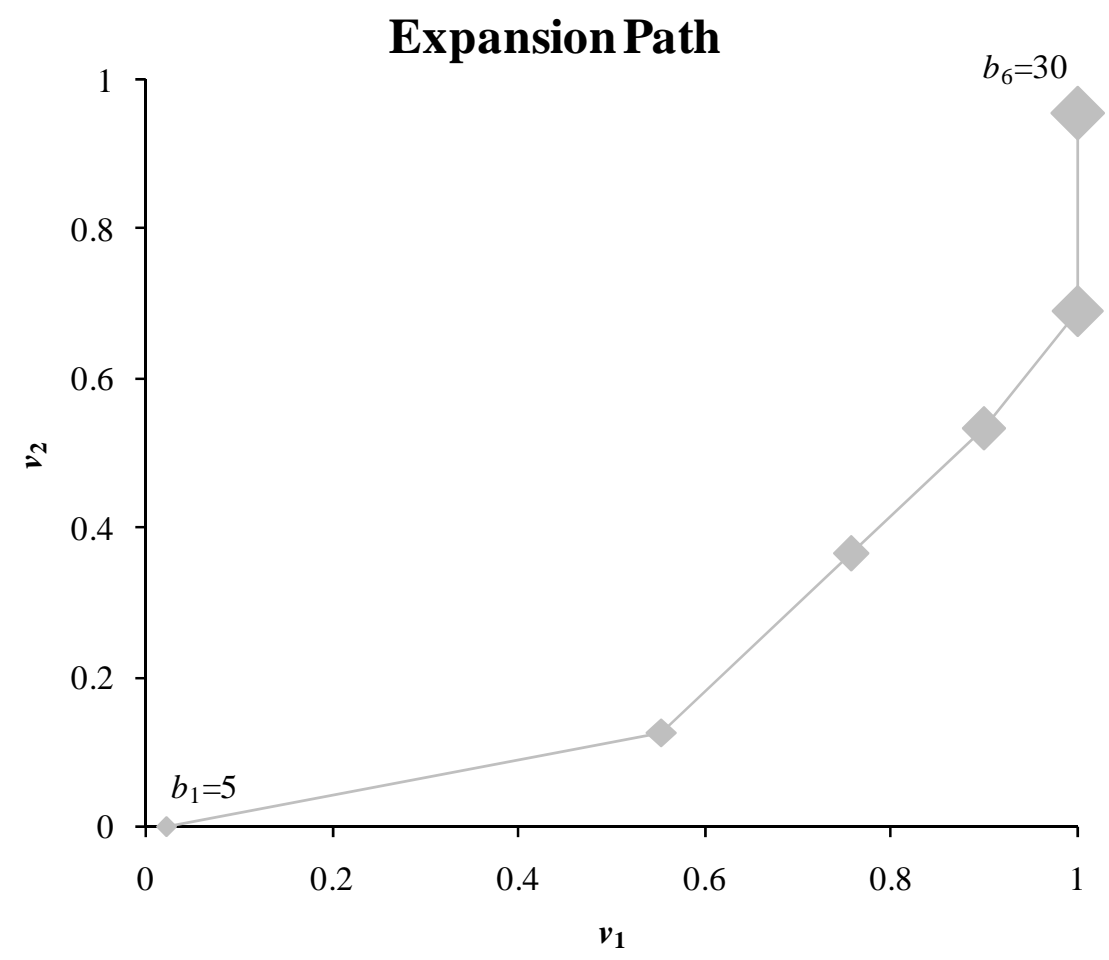

Figure 1. Expansion Path

Note. This graph shows the expansion path for a vendor as the budget increases from 5 to 30. The markers of increasing size show the vendor's attribute bundle proposals as the budget increases in increments of 5 .

Expansion paths will differ among vendors if the parameters of their cost functions $\left(\alpha_{i j}, \beta_{i j}\right)$ differ. Consider a second vendor (Vendor 2), whose individual-attribute cost functions are more convex. Specifically,

$$
\alpha_{12}=1.5, \alpha_{22}=1.5, \beta_{12}=2.7, \beta_{22}=2.7 \text {. }
$$

Vendor 2 is symmetric in the sense that he or she does not specialize in providing a particular attribute. Any asymmetry in Vendor 2's expansion path is due to the buyer having asymmetric preferences over the two attributes.

Applying the parameters in Equations 7 and 8 results in the expansion paths shown in Figure 2. The two piecewise linear expansion paths, one for each vendor, are based on 
the six possible budget levels. ${ }^{5}$ They illustrate optimum combinations of attribute values that can be produced by each vendor and offered to the buyer at the different funding levels.

\section{Expansion Paths - Differing Cost Functions}

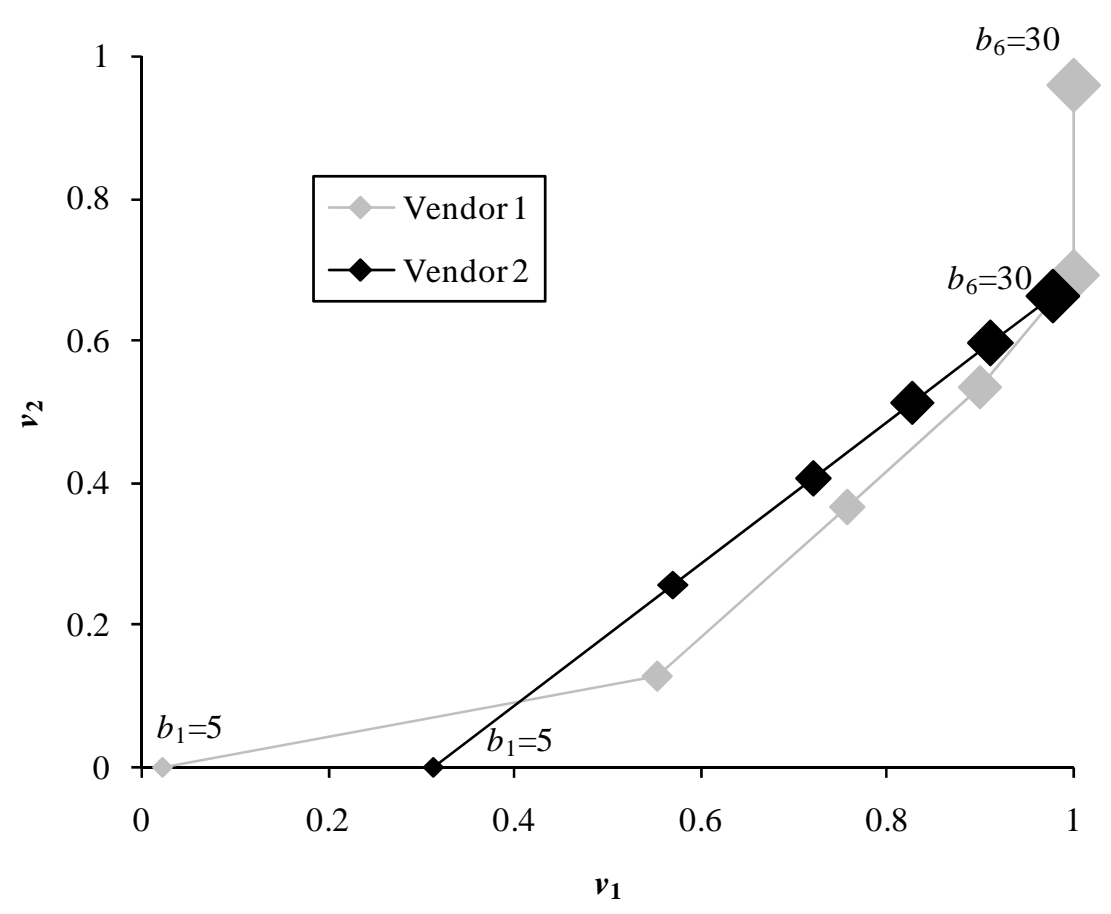

Figure 2. Expansion Paths-Differing Cost Functions

Note. This graph shows the expansion paths for two vendors with differing cost functions as the budget increases from 5 to 30 . The markers of increasing size show each vendor's attribute bundle proposals as the budget increases in increments of 5 .

Figure 2 reveals an interesting dynamic, which relates to one of the key insights of this study. Under optimistic assumptions about future budgets, it is clear that Vendor 1 will be preferred and selected as the winner. At relatively high budgets, Vendor 1 dominates Vendor 2. However, the reverse is true under a more pessimistic budget. Under severe budget constraints (e.g., $\$ 5$ million), it is clear that Vendor 2 will be preferred and selected as the winner. If a government buyer believes a significant budget cut is possible then selecting a dominant alternative under the optimistic budget scenario (Vendor 1) may be misleading. The dominated alternative (Vendor 2) should not be prematurely eliminated since it may, in fact, end up being the preferred vendor.

\footnotetext{
${ }^{5}$ Fitting a curve to the points might also be a reasonable approach. We use a piecewise linear form because we specifically would like every attribute bundle in the vendor's bid to fall on the expansion path because we believe this makes the method more transparent. We would advise the analyst and the buyer to use their discretion on which approach to take, based on the particular context of the auction.
} 
To illustrate this new expansion path approach more clearly, we compute $V\left(A_{j}\right)$ for each of the twelve attribute pairs shown in Figure 2. The two vendors' bids can then be plotted as curves in "budget-value" (or cost-effectiveness) space, as shown in Figure 3.

\section{Value by Budget Level}

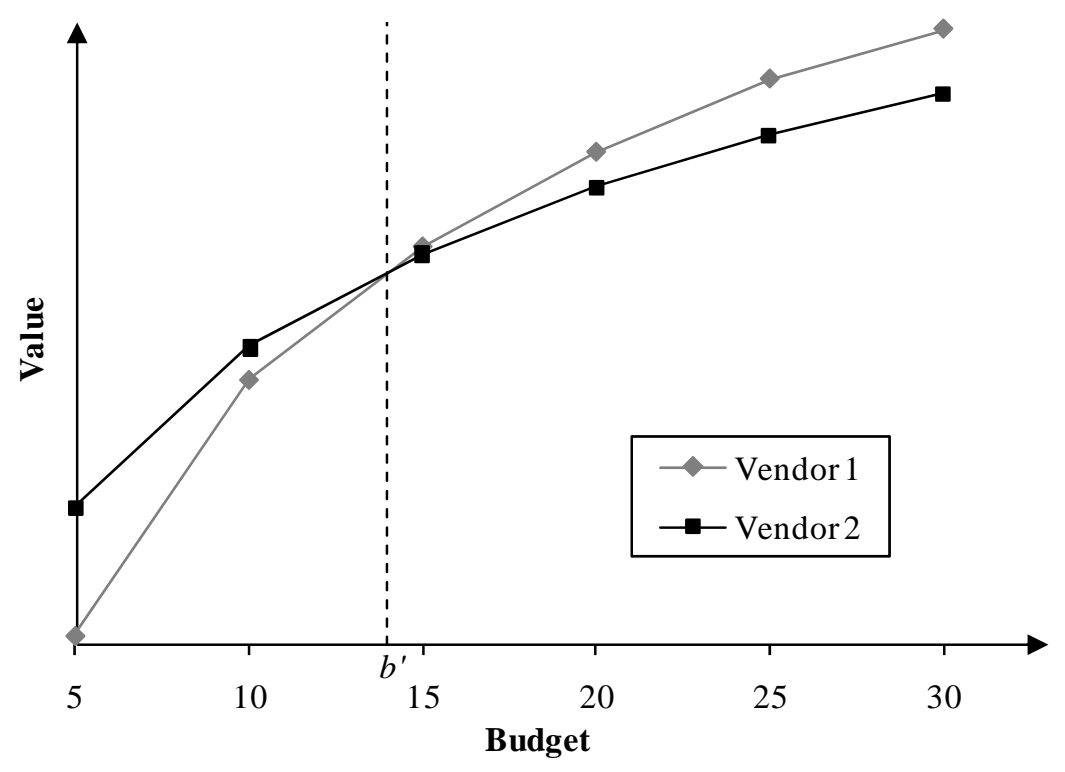

Figure 3. Value by Budget Level

Note. This graph shows the value provided by each vendor's bid for various budget levels.

Related to the expansion paths, the bids illustrated in Figure 3 are piecewise linear curves. We can think of each one as a function expressing the value to the buyer of the attribute bundles each vendor will provide over the range of possible budget levels. We will write this function for vendor $j$ as $\Omega_{j}(b)$, defined for all possible budget levels $b$.

The dynamic revealed in Figure 2 is illustrated more clearly in Figure 3 . It is apparent from Figure 3 that Vendor 2 dominates the competition for any positive budget below the switch-point, $b<b$ ', while Vendor 1 dominates for any budget above the switchpoint, $b>b^{\prime}$. As Quade (1989) also discusses, this observation suggests rethinking the simpler definition of dominance, which refers to points (not functions) in cost-effectiveness space.

Viewing alternatives as functions in budget-value space reveals that the point-based definition can be misleading. A static comparison that begins by assuming a relatively high fixed budget would eliminate Vendor 2 from further consideration. For example, consider offers from Vendor 1 and Vendor 2 based on optimistic budgets above b'. A technique that focuses on points and not functions would eliminate Vendor 2; yet, Figure 3 indicates that eliminating Vendor 2 prematurely could lead to a less desirable outcome if subsequent budget cuts resulted in an actual budget somewhere in the range of $0<b<b$ '. This observation suggests the need for a new approach to government vendor selection decisions. 
This switch-point phenomenon occurs as a result of differences in the two vendors' expansion paths. There is nothing unique about the particular functions chosen in our example. The same results can be obtained in many different ways, including with nonadditive forms of the buyer's value function. In fact, non-linear interactions between attributes are likely to magnify this effect. ${ }^{6}$

While the approach in this paper involves assessing the expansion paths by soliciting vendors' attribute bundle offers for multiple budgets, it may be possible for a government buyer to obtain similar information by soliciting price bids for multiple sets of performance requirements (i.e., specified attribute levels). This would have the advantage of not requiring the buyer to reveal a value function, but also the corresponding disadvantage of not allowing each vendor the flexibility to achieve the desired values with the least costly combinations of attribute levels. Using either approach, the buyer benefits by being able to incorporate affordability into the decision in a meaningful way when the budget is not known with certainty. In particular, the buyer gains the ability to view each alternative as a function in cost-effectiveness space, rather than as a single point.

Selecting a vendor based on points in cost-effectiveness space can lead to worse outcomes than expected, since there may be uncertainties present that are implicitly ignored. One example is the $\$ 8.8$ billion U.S. Navy and Marine Corps Intranet (NMCl) contract, which was awarded to Electronic Data System (EDS) in 2000. Wilson (2006) explains that EDS was the lowest bidder and that problems arose due to the scope of EDS task being much larger than expected by either party. Whether another vendor might have performed better than EDS given the expanded scope is unknown. (See Jordan, 2007, for more information on $\mathrm{NMCl}$.)

A second example is the U.S. Air Force's acquisition of the Boeing (then McDonnell Douglas) C-17 Globemaster III. This aircraft, commonly referred to as the C-17, is used as an airlifter for troops and cargo. McDonnell Douglas' C-17 proposal was selected in 1981, effectively ending the bidding process. However, a dollar amount was not specified until 1986, when the Air Force awarded McDonnell Douglas a $\$ 3.39$ billion contract. Even after 1986, the C-17 program was subjected to a great deal of change. Kennedy (1999) explains the following:

In addition, how much airlift was required for war plans was largely undefined. Securing necessary funding for the C-17 was simply an ordeal. That the program's funding fell victim to the budget axes wielded by Congress, DoD, and Air Force undermined the ultimate goal-timely operational delivery of the C-17.

As in the $\mathrm{NMCl}$ example, it would have been very difficult to foresee the eventual outcome for the $\mathrm{C}-17$ based simply on a cost-effectiveness point when the decision was made.

The sensitivity of vendor selection decisions to different funding scenarios is a fundamental result that arises in a wide variety of government procurement contexts and places a premium on affordability. In a constrained fiscal environment, we strongly recommend the adoption of an expansion path approach to guide government vendor selection decisions.

\footnotetext{
${ }^{6}$ For example, consider a multiplicative value function and suppose that one vendor has to incur a large cost to increase the value from 0 to 0.1 for one particular attribute. This vendor will offer bids of little value for low budgets but, depending on cost functions, may offer very attractive bids for higher budgets.
} 


\section{Budget Uncertainty}

A natural extension of the model is to consider a procurement auction in which the buyer assigns a probability distribution over the set of possible budgets. If the buyer believes that the realized budget will be $b$ with probability $p(b)$ or, in the continuous case, that $b$ has a probability density function $f(b)$ then the government vendor selection problem can be examined using a decision under uncertainty approach.

This adds a valuable new layer to the problem: We must now include the buyer's risk attitude, because he or she will be evaluating gambles over multiple possible values. We express risk attitudes through a utility function $U$, which takes the overall multiattribute value measure as its argument (see Dyer \& Sarin, 1982, or Matheson \& Abbas, 2005, for details). This approach allows us to separate the buyer's attitude toward risk and their strength of preferences over the attributes.

Given a value function $V$ and maximum and minimum achievable values, $U$ can be assessed using simple binary gambles. For example, the buyer could specify an attribute bundle $a^{0}$ that provides the minimum value (zero) and an attribute bundle $a^{*}$ that provides the maximum value (one) and then consider a hypothetical gamble in which he or she receives $a^{*}$ with probability $p$ and $a^{0}$ with probability 1-p. For any other attribute bundle $a^{\prime}$, $U\left(V\left(a^{\prime}\right)\right)$ would simply be the value of $p$ for which the buyer is indifferent between receiving the uncertain gamble and a certain value, $a$ '.

The government buyer's new problem is to select a vendor $j$ to maximize

$$
\sum_{b} p(b) U\left(\Omega_{j}(b)\right)
$$

or, in the continuous case, to maximize

$$
\int f(b) U\left(\Omega_{j}(b)\right) d b .
$$

That is, the government buyer maximizes the expected utility provided by the vendor, incorporating both the strength of its preferences over the vendor's attribute bundle proposals, expressed by $\Omega_{j}$, and its risk attitude, expressed by $U$.

Consider both the buyer and vendors' information used to generate Figure 2. Recall that the buyer places weights of 0.7 and 0.3 on Attributes 1 and 2 , respectively, while individual vendor production and cost characteristics are given by the parameters in Equations 7 and 8 ). Now suppose the buyer has the exponential utility function ${ }^{7}$

$$
U(V)=\frac{1-e^{-2 V}}{1-e^{-2}}
$$

where, as previously specified, $V$ varies between zero and one over the possible attribute bundles. The function and parameters given by Equation 11 represent a decision-maker who is risk averse. Note that since the minimum value of $V$ is zero and the maximum is one, $U(V)$ also varies between zero and one. Figure 4 illustrates the values and corresponding

\footnotetext{
${ }^{7}$ We chose the exponential function because it has constant absolute risk aversion, measured by a risk tolerance parameter (in this case, 0.5 ), making its assessment reasonably straightforward and understandable. It is commonly used in decisions under uncertainty, but the analysis could certainly be carried out using a different class of utility function if desired.
} 
utilities to the buyer of each vendor's attribute bundle proposals under the six possible budget scenarios, superimposed on the utility function defined by Equation 11.

\section{Bid Utilities}

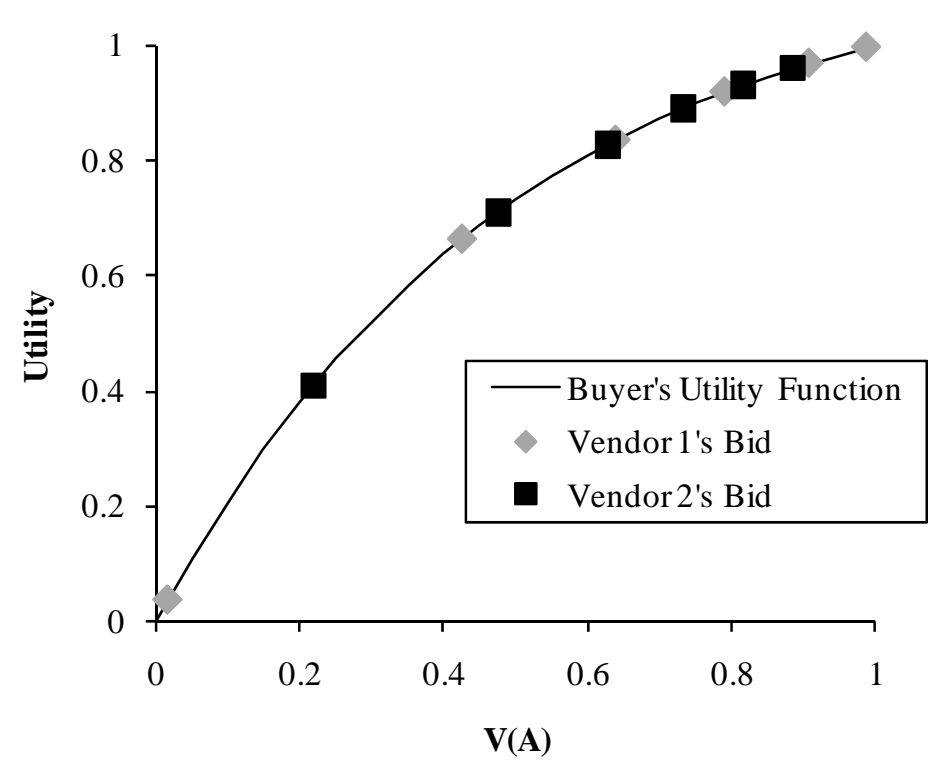

Figure 4. Bid Utilities

Note. This graph shows the buyer's utility function and the value and corresponding utility offered by each vendor for the six budget scenarios in the decision under uncertainty example.

Consider a scenario in which the buyer believes that $b_{1}, \ldots, b_{6}$ will occur with probabilities $0.1,0.15,0.35,0.25,0.1$, and 0.05 , respectively. Given these probabilities for the six budget levels and this particular buyer's preferences, the expected utility if Vendor 1 is selected is 0.771 , as opposed to 0.800 if Vendor 2 is selected. While this aggregate result suggests that our buyer should select Vendor 2, disaggregating the vendor selection problem offers additional insights.

The bundle of attributes provided by Vendor 1 would be more desirable for budget levels $15,20,25$, and 30 , one of which is likely to occur with a probability of 0.75 . However, in the case of a very low budget, Vendor 1's attribute bundle would be far less desirable. Yet, the expected values of the two bids are nearly identical. Such insights would be nearly impossible to obtain when presented with only a single bid from each vendor for the most likely budget, $b=15$. More revealing and robust analysis is only feasible if the buyer solicits bids from the vendors over multiple possible budget levels.

Constructing a gamble over possible overall values is extremely difficult if a vendor's bid consists of only one attribute bundle for a single budget, rather than a set of attribute bundles for multiple budgets. A decision under uncertainty approach requires decisionmakers to place a value on all possible outcomes. The procurement auction framework advocated in this paper ensures that these outcomes are fully specified. 


\section{Conclusion}

This paper offers a new approach to government vendor selection decisions in major public procurements. The paper describes a simple three-stage, multiattribute procurement process for government vendor selection decisions. It allows the buyer to incorporate the government's preferences over multiple attributes, and it allows each vendor to offer its best possible bid based on the budget estimate for the program and on each vendor's cost structure. The model operationalizes a version of the popular concept of cost as an independent variable (CAIV). The results of this study reveal the importance in the public sector of including costs as part of a budget constraint, rather than incorporating costs directly in the buyer's value and utility function.

The model developed in this paper allows vendors to submit bids for a range of possible budget levels. This leads to the generation of an expansion path for each vendor, which illustrates how each vendor's bid improves as budgets increase. Most importantly, it is demonstrated that a vendor whose bid is dominated at one particular budget level can easily end up being the winner at another budget level. This makes it vital for procurement agencies to rethink traditional public sector bid solicitations. Instead of viewing each vendor as a single point in cost-effectiveness space, it is important for governments to view each vendor as a curve in budget-value space. In economies where affordability is a priority and where budgets are likely to change over time, the approach proposed in this paper can result in better choices for voters and taxpayers since it ensures vendors are not prematurely eliminated from consideration.

Finally, since precise funding levels may not be known with certainty when vendor selection decisions are made, we explicitly model vendor selection as a decision under uncertainty. In this case, the buyer assigns a probability distribution over all possible budgets (funding levels) while a utility function captures the buyer's attitude toward risk. This methodology enables buyers to generate expected utilities from vendor proposals, providing a valuable new approach and metric for government vendor selection decisions.

The approach in this paper can be thought of as a strategic choice of auction mechanism for a buyer when a range of budget authorities for the program can be estimated and products are differentiated and complex. The approach combines the competitive advantages of auctions with the flexibility of decisions based on multiple attributes of a product, all while incorporating considerations of affordability when the budget level is not known with certainty.

\section{References}

Beil, D., \& Wein, L. (2003). An inverse-optimization-based auction mechanism to support a multiattribute RFQ process. Management Science, 49(11), 1529-1545.

Blondal. (2006). International experience using outsourcing, public-private partnerships, and vouchers. In J. M. Kamensky \& A. Morales (Eds.), Competition, choice, and incentives in government programs (pp. 121-159). Lanham, MD: Rowman \& Littlefield.

Buede, D. M., \& Bresnick, T. A. (1999). Applications of decision analysis to the military systems acquisition process. Interfaces, 22(6), 110-125.

Che, Y. (1993). Design competition through multidimensional auctions. RAND Journal of Economics, 24(4), 668-680. 
Dyer, J. S., \& Sarin, R. K. (1979). Measurable multiattribute value functions. Operations Research, 27(4), 810-822.

Dyer, J. S., \& Sarin, R. K. (1982). Relative risk aversion. Management Science, 28(8), 875886.

Federal Acquisition Regulation (FAR), 48 C.F.R. ch. 1 (2005).

Hitch, C., \& McKean, R. (1967). The economics of defense in the nuclear age. Cambridge, MA: Harvard University Press.

Jordan, K. (2007). The NMCI experience and lessons learned. The consolidation of networks by outsourcing. Case Studies in National Security Transformation, No. 12.

Keeney, R. L. (1992). Value-focused thinking: A path to creative decisionmaking. Cambridge, MA: Harvard University Press.

Keeney, R. L. (2004). Making better decision makers. Decision Analysis, 1(4), 193-204.

Keeney, R. L., \& Raiffa, H. (1976). Decisions with multiple objectives: Preferences and value trade-offs. New York, NY: John Wiley and Sons.

Kennedy, B. R. (1999). Historical realities of C-17 program pose challenge for future acquisitions. Program Manager Magazine, 28(6), 70-78.

Kirkwood, C. (1997). Strategic decision making. New York, NY: Duxbury Press.

Kirkwood, C. W., \& Sarin, R. K. (1980). Preference conditions for multiattribute value functions. Operations Research, 28(1), 225-232.

Larsen, R. F. (2007). The evolution of the Pentagon's strategic warfighting resources and risk process. Land Warfare Papers, No. 64.

Loerch, A. G., Koury, R. R., \& Maxwell, D. T. (1999). Value added analysis for army equipment modernization. Naval Research Logistics, 46(3), 233-253.

Matheson, J. E., \& Abbas, A. E. (2005). Utility transversality: A value-based approach. Journal of Multi-Criteria Decision Analysis, 13(5-6), 229-238.

McAfee, R. P., \& McMillan, J. (1987). Auctions and bidding. Journal of Economic Literature, 25(2), 699-738.

Michael, R. T., \& Becker, G. S. (1973). On the new theory of consumer behavior. The Swedish Journal of Economics, 75(4), 378-396.

Milgrom, P. (1989). Auctions and bidding: A primer. Journal of Economic Perspectives, 3(3), 3-22.

Parkes, D., \& Kalagnanam, J. (2005). Models for iterative multiattribute procurement auctions. Management Science, 51(3), 435-451.

Parnell, G. S. (2007). Value-focused thinking using multiple objective decision analysis. In A. Loerch \& L. Rainey (Eds.), Methods for conducting military operational analysis: Best practices in use throughout the Department of Defense (pp. 619-656). Alexandria, VA: Military Operations Research Society.

Pratt, J. W., Raiffa, H., \& Schlaifer, R. (1964). The foundations of decision under uncertainty: An elementary exposition. Journal of the American Statistical Association, 59(306), 353-375.

Quade, E. S. (1989). Analysis for public decisions (Rev. ed. by G. M. Carter). New York, NY: North-Holland.

Sproles, N. (2000). Coming to grips with measures of effectiveness. Systems Engineering, $3(1), 50-58$.

Wilson, L. E. (2006). NMCl: The silver lining. EWS Contemporary Issue Paper. 
Wise, R., \& Morrison, D. (2000). Beyond the exchange-The future of B2B. Harvard Business Review, 78(6), 86-96.

Written testimony of M. Sullivan, Government Accountability Office, before the Committee on the Budget, House of Representatives, 111th Cong. (2009, March 18). 